\title{
Essential long chain polyunsaturated fatty acids in muscle tissue of freshwater fish Labeo calbasu under different cooking processes
}

\author{
${ }^{1}$ Nusrat N. Memon*. ${ }^{2}$ Farah N. Talpur. ${ }^{2}$ Muhammad I. Bhanger. \\ ${ }^{1}$ G. Zuhra. Memon. ${ }^{1}$ Moina A. Mughal. ${ }^{1}$ Kulsoom U.Abbasi. ${ }^{2}$ Sana Jawaid \\ IDr. M.A. Kazi Institute of Chemistry, University of Sindh, Jamshoro, Pakistan. \\ 2National Center of Excellence in Analytical Chemistry, University of Sindh, Jamshoro, Pakistan.
}

\begin{abstract}
The effect of different cooking methods (Raw, steaming, microwave cooking, baking, grilling, pan frying and deep frying) on proximate composition and fatty acid profile of Labeo calbasu fish species from Pakistan were analyzed to determine the nutritional qualities in terms of the long chain n-3 PUFA particularly EPA and DHA. In all cooking methods moisture content decrease and protein content increased as compare to raw sample. The moisture content of fish sample seemed to be inversely related to the total extractable lipid content. In steamed, microwave, baked, grilled and pan fried methods MUFA were the abundant fatty acids followed by SFA and PUFA. Deep fried fish sample had the opposite trend having highest PUFA as contrast to MUFA and SFA. Long chain n-3 PUFA were found higher in contrast to n-6 PUFA in all other cooking methods excluding deep frying. The results indicates that steamed and grilled cooking are the best cooking method for healthy eating as they contain more n-3 PUFA (EPA and DHA). Losses of n-3 content in pan fried and deep fried fish were higher than those of fish cooked by other methods.
\end{abstract}

Key words: Labeo calbasu, Fatty acids, Proximate composition, Cooking methods, Gas chromatography.

\section{Introduction}

In last decades polyunsaturated fatty acids (PUFAs) of $n-3$ family have been recognized to be essential components for humans diet, these acids particularly the long chain $n-3$ PUFA such as eicosapentaenoic acid, 20:5 (EPA) and docosahexaenoic acid, 22:6(DHA) [1]. The regular consumption of these $n$-3 PUFA is considered to be important because of their role in the prevention of several diseases including cancer, cardiovascular, stroke, inflammatory disorders, depressions, neural development, immune systems, type 2 diabetes and insulin resistance, reduce blood LDL cholesterol, hypertension and have antithrombotic, antiinflammatory, antiarrhythmic and vasodilatory properties $[2,3,4,5,6]$.

Aquatic ecosystems are known to be the main source of essential long chain $n$-3 PUFAs in biosphere, thereby humans obtain principal part of EPA and DHA by consuming fish, no other food group is naturally as rich in long chain $n$-3 PUFA as are fish, macro algae and other seafood $[7,8]$.

Fish is generally consumed in a cooked state and different cooking processes have a negative effect on the $n-3$ fatty acid content. Cooking destroys pathogenic and spoilage microorganisms, inactivates enzymes and enhances desirable flavors and tastes of fish flesh [9]. However, owing to the thermal sensitivity of a broad number of fish constituents and nutrients several detrimental effects due to cooking have been reported: i.e., heat degradation of nutrients, oxidation of vitamins and lipids, leaching of water-soluble vitamins, minerals and proteins, and toughening and drying of sensitive protein tissues [10,11]. Meanwhile, the long-chain PUFA such as EPA and DHA, are considered to be especially susceptible to oxidation during heating and other culinary treatments $[12,13,14,15]$.

At present consumers do not have information on how best to prepare fish to obtain the maximum $n-3$ fatty acid content. No literature is available focusing on the effect of cooking method on the fatty acid profile of fish in this area specifically. Therefore, the aim of present work was to study the effects of different cooking methods (Raw, steaming, microwave, baking, grilling, pan frying and deep frying) on PUFA contents and proximate composition in Labeo calbasu fish species common in Pakistani markets.

\section{Materials And Methods}

\subsection{Sampling:}

Samples of freshwater fish Labeo calbasu were obtained from a local fish market (Hyderabad, Pakistan) weighing approximately $1.5 \pm 0.05 \mathrm{~kg}$. The whole fish were eviscerated, washed and immediately transported to the laboratory in ice containing boxes. Fresh fish were washed with tap water several times to remove slime and adhering blood, they were then prepared using common household practices, such as removing head, backbone, skin, tail and fin. 


\subsection{Cooking Methods:}

Fillets subsequently divided into seven homogeneous groups. One group was kept fresh-raw and used as reference. The other six were cooked by steaming, microwave, baking, grilling, pan frying and deep frying methods.

\subsubsection{Steaming:}

A total of $1.5 \mathrm{~L}$ of filtered tap water was poured into the bottom of stainless steel home steamer and heated to boil. The fish fillets were then steamed for $12-14 \mathrm{~min}$, and then fillets were allowed to cool for 20 $\min$.

\subsubsection{Microwave cooking:}

The fish fillets were placed on a flat dish without any cover. Microwave (Panasonic NN-K573 MF) cooking was carried out at a frequency of $2450 \mathrm{MHZ}$; at high power for 4-5 min. cooked samples were air cooled for $20 \mathrm{~min}$.

\subsubsection{Baking:}

Baking of fish fillets was performed in a conventional oven (Balay, Zaragoza, Spain) at $200{ }^{\circ} \mathrm{C}$ for 22 min. The process finished when the inner fillet temperature, measured with a quartz electronic thermometer (Huger, Oregon Scientific Trade Mark, Germany), ranged from 60 to $70{ }^{\circ} \mathrm{C}$. The cooked samples were air cooled for $20 \mathrm{~min}$.

\subsubsection{Grilling:}

The grilling of fish was performed for 13-15 min in an electrical griller (Fagor, SEM-60) set at $120^{\circ} \mathrm{C}$. The fish fillets were turned in the middle of the cooking time. The cooked samples were air cooled for $20 \mathrm{~min}$.

\subsubsection{Pan Frying:}

Fish Fillets fried for $5 \mathrm{~min}$ in sunflower oil, which was preheated to $180{ }^{\circ} \mathrm{C}$ for $2 \mathrm{~min}$ in a household frying pan. The temperature of the oil was monitored by a digital steel thermometer and the heating was slowed down when the oil temperature reached $165^{\circ} \mathrm{C}$. The frying oil used was such it only covered $1 / 3$ of the thickness of the fish Fillets and fresh oil was used for every group of frying. The pans were washed, cleaned and dried after each group of frying. The Fillets were turned after $3 \mathrm{~min}$. After frying, the fish Fillets were allowed to be air cooled for $20 \mathrm{~min}$.

\subsubsection{Deep frying:}

The fish samples were placed in a wire mesh basket and immersed in sunflower oil in a deep fryer for 5 min at $180^{\circ} \mathrm{C}$. After frying, the basket was shaken and the samples were placed on absorbent paper towels.

\subsection{Proximate analysis:}

Homogenized fish meat was subjected to moisture and ash analysis using Association of the Official Analytical Chemists (AOAC 1995) methods. Crude protein content was calculated by converting the nitrogen content, determined by Kjeldahl method (method 981.10 for meat, AOAC 1990). Lipid content was determined by the method of Bligh and Dyer (1959).

\subsection{Fatty acid analysis:}

Fatty acid methyl esters were prepared by saponification and esterification of lipid by standard IUPAC method. Hexane layer, containing the FAME, was placed into a GC vial. The vial was capped and placed at 20 ${ }^{0} \mathrm{C}$ until GC analysis. The fatty acid methyl esters (FAMEs) were analyzed on a Perkin Elmer gas chromatograph model 8700 (Perkin-Elmer Ltd., Buckinghamshire, England) fitted with nonbonded biscynopropyl siloxane stationary phase, polar capillary column Rt-2560 $(100 \mathrm{~m} \times 0.25 \mathrm{~mm}) 0.2 \mu \mathrm{m}$ film thickness (Supelco, PA, USA) and an FID. Oxygen-free nitrogen was used as a carrier gas at a flow rate of 3.5 $\mathrm{mL} / \mathrm{min}$. The initial oven temperature was $150{ }^{\circ} \mathrm{C}$ at rate of $4 \mathrm{~min}$ which was raised to $190{ }^{\circ} \mathrm{C}$ at a rate of 2 ${ }^{0} \mathrm{C} / \mathrm{min}$ and further to $220{ }^{\circ} \mathrm{C}$ held for $7 \mathrm{~min}$. The injector and detector temperature were set at $260{ }^{\circ} \mathrm{C}$ and 270 ${ }^{0} \mathrm{C}$, respectively. A sample volume of $1.0 \mu \mathrm{L}$ was injected. All of the quantification was done by a built-in datahandling program provided by the manufacturer of the gas chromatograph (Perkin-Elmer). The fatty acids methyl esters were identified by comparing the retention time of the samples and appropriate fatty acids methyl esters standards, purchased from Sigma (St. Louis, MO, USA). 


\subsection{Proximate composition:}

\section{Results And Discussions}

The changes in proximate compositions in raw and after different cooking process of Labeo calbasu fish are shown in Table 1. The proximate compositions of raw fish is comparable with silver catfish (Rhamdia quelen) studied by Jucieli et al [16]. The moisture content of Labeo calbasu fish was ranged from 56-76.05\%, which was decreased after cooking, lesser changes (4-20\%) was observed in steamed cooking as compared to other forms of cooked fish samples. Minimum moisture content was characteristic of deep fried fish (56\%) and maximum moisture content was found for steamed-cooked fish (72.49\%). Generally, the moisture content of fish sample seemed to be inversely related to the total extractable lipid content. This was observed in the deep fried Labeo calbasu fish which had the lowest moisture content and the highest total extractable lipid content. These results are in agreement with those of Garci'a et al [17]. Increase in fat content of the fried Labeo calbasu fish indicates absorption of oil during the frying process. Similar results were found for sardines fried in sunflower oil $[13,18]$. The author has concluded from his observations that increase in fat content is due to the penetration of oil on the food after water is partially lost by evaporation.

Table-1 Proximate composition (\%) in Raw and Cooked Labeo calbasu fish meat

\begin{tabular}{lllll}
\hline Cooking methods & Moisture & Ash & Protein & Lipid \\
\hline Raw & $76.05^{\mathrm{a}} \pm 0.02$ & $1.15^{\mathrm{a}} \pm 0.01$ & $20^{\mathrm{c}} \pm 0.03$ & $2.57^{\mathrm{b}} \pm 0.01$ \\
Fried & $58.99^{\mathrm{a}} \pm 0.03$ & $2.68^{\mathrm{c}} \pm 0.15$ & $30.01^{\mathrm{a}} \pm 0.11$ & $8.32^{\mathrm{a}} \pm 0.01$ \\
Steamed & $72.49^{\mathrm{b}} \pm 0.05$ & $2.11^{\mathrm{b}} \pm 0.04$ & $23^{\mathrm{c}} \pm 0.12$ & $2.4^{\mathrm{c}} \pm 0.12$ \\
Micro waved & $65.73^{\mathrm{c}} \pm 0.12$ & $1.28^{\mathrm{a}} \pm 0.01$ & $29^{\mathrm{b}} \pm 0.04$ & $3.76^{\mathrm{b}} \pm 0.05$ \\
Grilled & $66.84^{\mathrm{b}} \pm 0.09$ & $1.66^{\mathrm{a}} \pm 0.03$ & $27^{\mathrm{c}} \pm 0.05$ & $4.5^{\mathrm{a}} \pm 0.02$ \\
Backed & $68.28^{\mathrm{c}} \pm 0.12$ & $1.52^{\mathrm{c}} \pm 0.05$ & $25^{\mathrm{a}} \pm 0.01$ & $5.2^{\mathrm{c}} \pm 0.03$ \\
Deep fried & $56^{\mathrm{a}} \pm 0.04$ & $2.73^{\mathrm{a}} \pm 0.02$ & $31.27^{\mathrm{b}} \pm 0.12$ & $10^{\mathrm{b}} \pm 0.01$ \\
\hline
\end{tabular}

$*$ Values are given as mean \pm SD from triplicate determinations.

Different superscripts in the same column indicate significant differences $(\mathrm{p}<0.05)$.

The ash content increased after all analyzed cooking methods, except for the steamed cooking, while the protein and fat content was found highest in deep fried process. However the analyzed steamed cooking fish contains the same range of fat content as in raw fish Puwastien et al [19] have reported similar findings. The increase in the fat, protein and ash contents in cooked Labeo calbasu fish by different process are due to the reduction of moisture as supported by previous studies [17]. During backing of Labeo calbasu fish, water lost and decrease in moisture content was observed with a consequent increase in fat, protein and ash contents. However dehydration was lower than during frying, these changes were similar to those found by Gall, et al [20], in rainbow trout and in sardines [17] and in white fish by Gokoglu et al [21].

There was a significant net increase in protein levels in cooked fish when compared with the raw fish. This suggests that protein nitrogen was not lost during cooking. Higher protein content was in deep fried (31.27\%) followed by pan fried (30.01\%), microwave (29\%), grilled (27\%),backed (25\%) and steamed cooked fish $(23 \%)$ than in raw fish $(20 \%)$, this is accordance with the findings of Gokoglu et al [21]. These variations appear to be related to the rate of change in food temperature (quicker in frying), and the process temperature (higher in grilling than in oven-baking).

\subsection{Changes in fatty acid composition:}

The fatty acid profile in the meat of Labeo calbasu fish is shown in Table 2. The most abundant fatty acid found in raw Labeo calbasu fish meat was oleic acid (18:1 n-9), palmitic acid (16:0) palmitoleic acid (16:1) docosahexanoic acid (22:6), linoleic acid (18:2), stearic acid (18:0) and ecosapetanoic acid (20:5). These findings are in agreement with those obtained by Jucieli et al [16] for Brazil silver catfish and Shirai et al [22] for Japanees and Thai catfish. Steaming, microwaving, backing and grilling marginally affected the Labeo calbasu fillets fatty acid contents. Conversely pan frying and deep frying of Labeo calbasu fillets showed great changes in the fatty acid profile when compared to raw samples, probably due to oil absorption during the frying process.

In agreement with Jucieli et al [16] and Garc1'a- et al [17] the changes were not homogeneous for the different fatty acids because some fatty acids decreased, while others increased. The changes observed were dependent on the composition of the frying oil. Among the raw and the different cooking (steamed, microwaved, baked, grilled and pan fried) methods for Labeo calbasu fish meat lipid, MUFA were the most abundant fatty acids followed by SFA and PUFA similar findings were also reported from New Zealand by 
Danaé et al [23] for king salmon (Oncorhynchus tshawytscha). Deep fried fish samples had the opposite trend having highest PUFA as contrast to MUFA and SFA.

Table 2 Fatty acid profile for Labeo calbsu fish meat in Raw and Different cooking methods (g/100g FA).

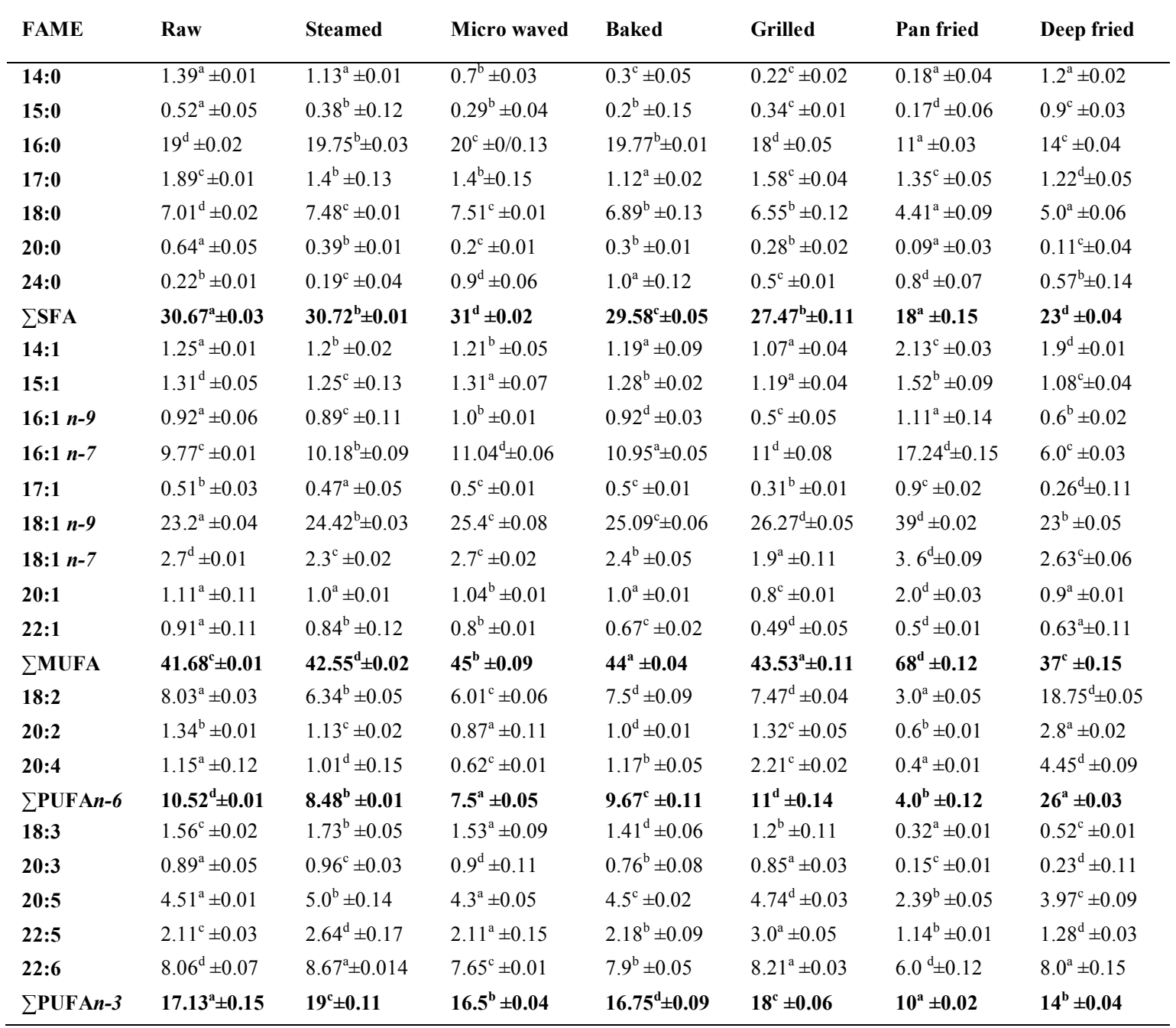

$*$ The values are given as mean \pm SD from triplicate determinations. Values in the same line with different letters are significantly different at $\mathrm{p}<0.05$.

The highest level of MUFA were found in pan fried cooking (68\%) compared to the microwave cooking (45\%), backed cooking (44\%), grilled cooking (43.53\%), steamed (42.55\%), deep fried (37\%) and in raw fish (41.68). In Labeo calbasu fish the primary MUFA identified for all cooking methods were oleic acid. This FA in lipid of Labeo calbasu tissue was calculated to be at levels of 39\% of total MUFA in pan fried, $26.27 \%$ in grilled, $25.4 \%$ in microwave, $25.09 \%$ in backed, $24.42 \%$ in steamed, $23.2 \%$ in raw and $23 \%$ in deep fried cooking. In the present study, the second most important MUFA was palmitoleic acid. Highest level of palmitoleic acid was found in pan fried while lowest in deep frying cooking.

The SFA content ranged from $18-31 \%$ of total fatty acids. The SFA were dominated by palmitic acid and stearic acid. Highest level of both fatty acids were found in micro wave cooking $20 \%$ and $7.51 \%$ while lowest in pan frying $11 \%$ and $4.41 \%$ respectively.

The $n-6$ PUFA were dominated by linoleic acid as the most abundant $n-6$ fatty acid among all cooking methods. The highest level of linoleic acid and total $n-6$ fatty acid were found in raw fish fillets as compare to all cooking methods except deep frying $(\mathrm{p}<0.05)$, which possess higher contents of linoleic acid and total $n-6$ fatty acid (18.75and 26\%) as a direct result of uptake from the frying oil as reported earlier [23]. On comparing the raw and cooked fish labeo calbasu is a very rich source of $n-3$ PUFA. Long chain $n-3$ PUFA were found higher in contrast to $n-6$ PUFA in all fish samples except deep fried one. Long chain $n-3$ fatty acids were essential for human health, the highest proportion of these were found in steamed cooking method followed by grilled, raw, backed, microwave, and deep fried methods. The results indicates that steamed and grilled cooking are found to be the best cooking method for healthy eating as they contain more $n-3$ PUFA as compare to raw 
meat. Losses of $n-3$ content in pan fried and deep fried fish were higher than those of fish cooked by other methods as shown in Figure 1.

Fig. 1 Comparison in between $n-3$ and $n-6$ PUFA among raw and different cooking process

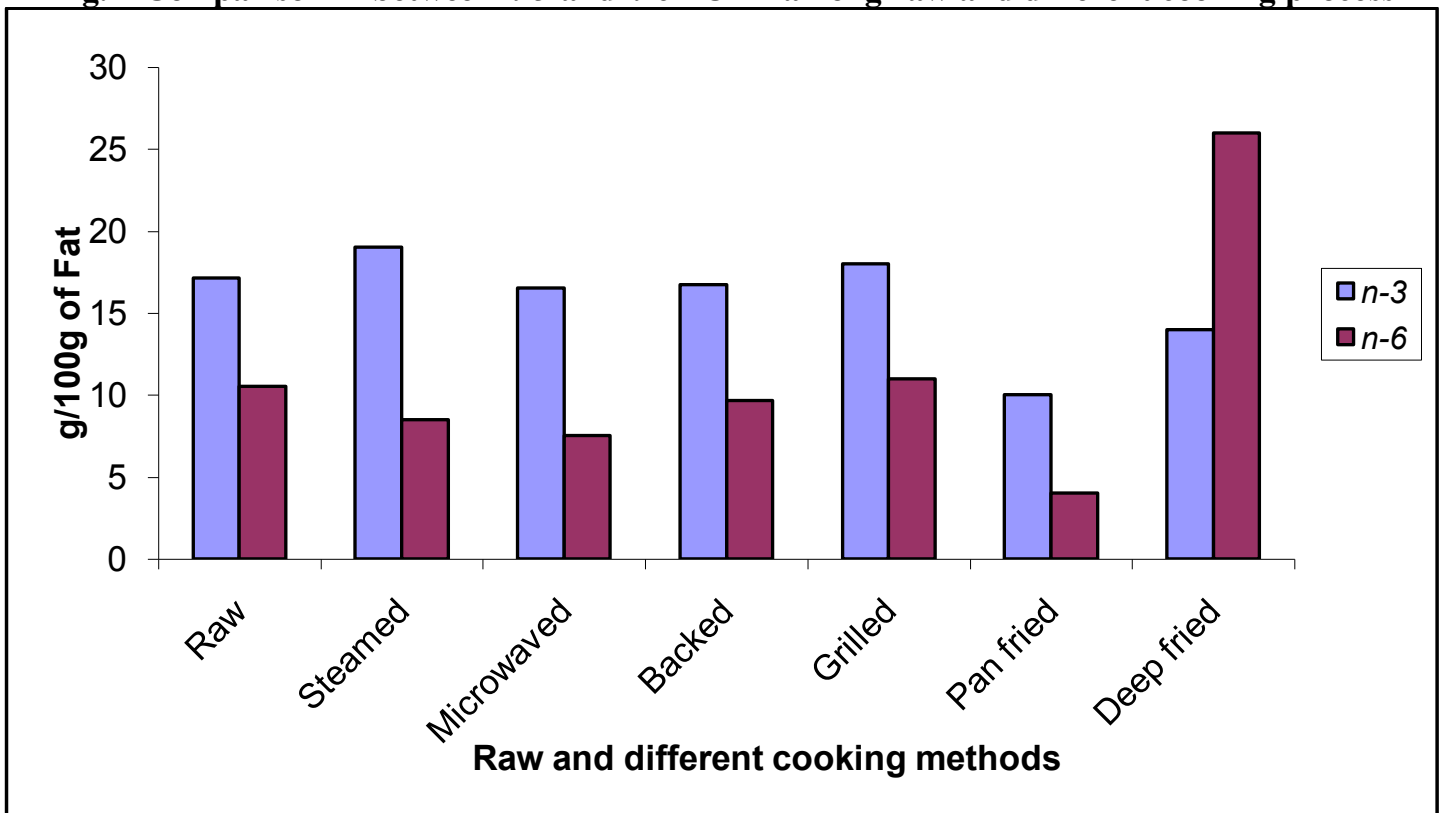

In raw and cooking procedures, DHA and EPA are the most abundant $n-3$ fatty acids; EPA and DHA content were found higher in steamed and grilled processed fish in contrast to raw fish. Losses of DHA and EPA content in pan fried fish sample were higher than those of fish cooked by other methods as depicted in Figure 2.

Michail et al [1] reported that besides content of PUFAs, ratio of $n-3 / n-6$ acids is known to be of dietetic importance because it is the key factor for balanced synthesis of eicosanoids in organism. According to current WHO recommendations, daily ratio of $n-3 / n-6$ in total human diet should not be higher than $1: 5$, In tissues of

Fig. 2 Comparison in between EPA and DHA among raw and different cooking process

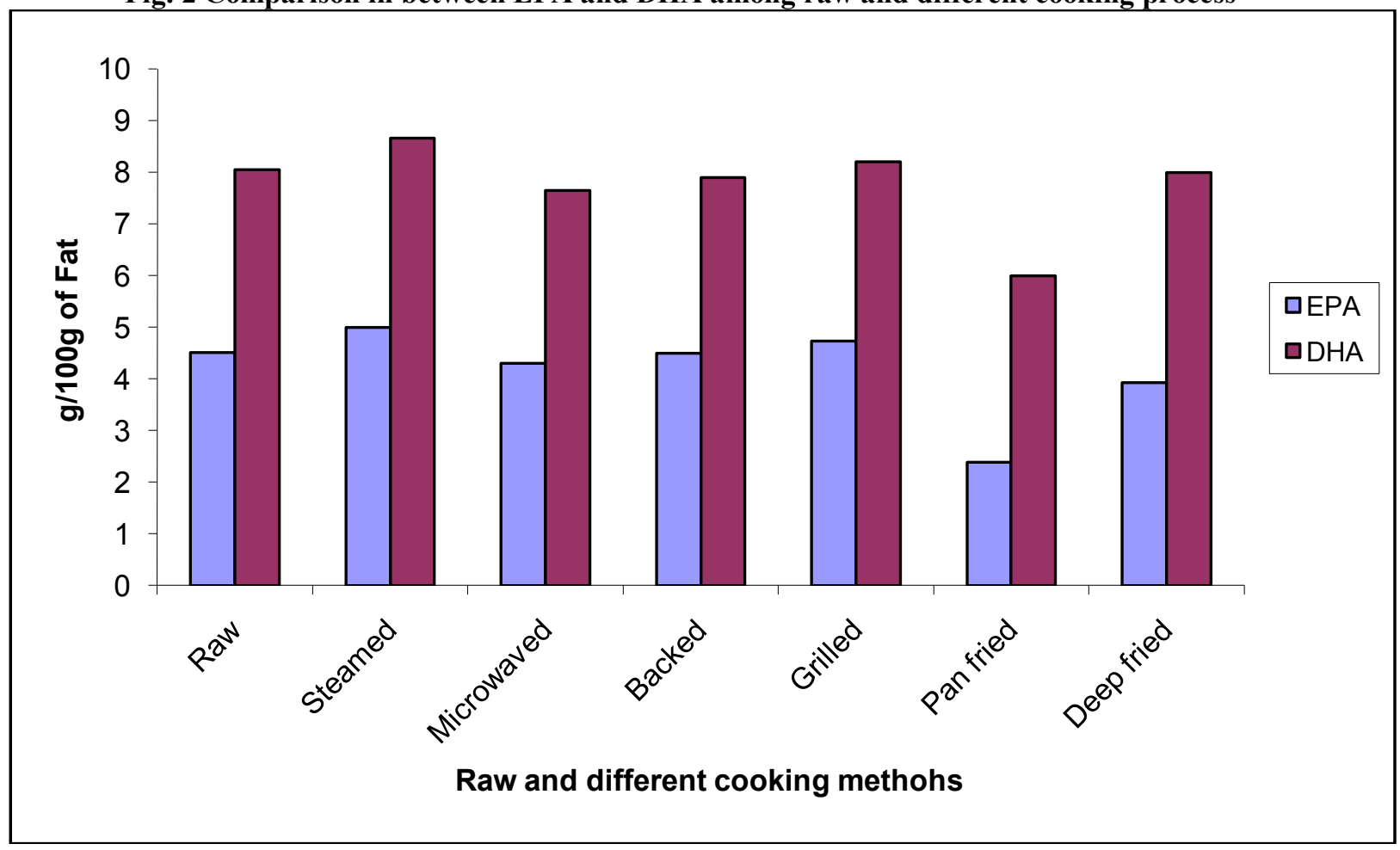

marine fish the ratio on the average varied from 5 to 10 , and in freshwater fish from 1 to 4 [24]. In present study $n-3 / n-6$ ratio is 1.63 for raw sample increase for all cooking method from 1.64 to 2.6 except deep frying method 
in which reduced to 0.54 . These results are comparable with sardine fish $n-3 / n-6$ ratio (2.2-0.2) as reported by Tarley et al [15].

\section{Conclusion}

Raw and cooked labeo calbsu is very rich source of $n$-3 PUFA. Losses of $n-3$ content in pan fried and deep fried fish were higher than those of fish cooked by other methods. Deep fried fish showed a significant increase in $n-6$ fatty acids due to uptake of linolenic acid from the frying oil. On comparing the raw and cooked fish, the results indicate that cooking had considerable effect on proximate composition and fatty acid composition. It can be concluded that the steaming and grilling contain more $n-3$ PUFA in fish fillets particularly EPA and DHA and considered as the best cooking method for labeo calbasu as for as healthy eating is concerned.

\section{Acknowledgement \\ This study was funded and supported by the NATIONAL CENTER OF EXCELLENCE IN ANALYTICAL CHEMISTRY, SINDH UNIVERSITY JAMSHORO PAKISTAN.}

\section{References}

[1]. Michail, I.G. Nadezhda, N.S. Galina, A.G. Sevilia, M.D. Galina, S.K. 2006. Effect of way of cooking on content of essential polyunsaturated fatty acids in muscle tissue of humpback salmon (Oncorhynchus gorbuscha). Food Chem 96, 446-451.

[2]. Lauritzen, L. Hansen, H.S. Jorgensen, M.H. Michaelsen, K.F. 2001. The essentiality of long chain n-3 fatty acids in relation to development and function of the brain and retina. Prog Lipid Res. 40, 1-94.

[3]. Broadhurst, C.L. Wang, Y. Crawford, M.A. Cunnane, S.C. Parkington, J.E. Schmidt, W.F. 2002. Brain-specific lipids from marine, lacustrine, or terrestrial food resources: potential impact on early African Homo sapiens. Comp Biochem Physiol. 131, 653-673.

[4]. Kris-Etherton, P.M. Harris, W.S. Appel, L.J. 2003. N-3 fatty acids and cardiovascular disease - new recommendations from the American Heart Association. Arterioscler Thromb Vasc Biol. 23(2), 151-152.

[5]. Din, J.N. Newby, D.E. Flapan, A.D. 2004. Science, medicine, and the future N- 3 fatty acids and cardiovascular disease fishing for a natural treatment. Br Med J. 328(7430), 30-35.

[6]. Lombardo, Y. Chicco, A.G. 2006. Effects of dietary polyunsaturated $n_{-} 3$ fatty acids on dyslipidemia and insulin resistance in rodents and humans. A review. J. Nutr. Biochem. 17:1-13.

[7]. Arts, M.T. Ackman, R.G. Holub, B.J. 2001. Essential fatty acids', in aquatic ecosystems: a crucial link between diet and human health and evolution. Can J Fish Aquat Sci. 58,122-137.

[8]. Isabelle, S. Lindsey, H. Katleen, R. Caroline, H. Stefaan, D. H. Stefaan, D. S. John, V.C. 2006. Effects of pan-frying in margarine and olive oil on the fatty acid composition of cod and salmon. Food Chem. 98, 609-617.

[9]. Alicia, R. Nicola's, C. Jose', M .C. Santiago, P. Aubourg, 2008. Changes in the flesh of cooked farmed salmon (Oncorhynchus kisutch) with previous storage in slurry ice $\left(-1.5{ }^{\circ} \mathrm{C}\right)$. LWT-Food Sci Technol. 41,1726-1732.

[10]. Aitken, A. Connell, J. 1979. Fish. In R. Priestley (Ed.), Effects of heating on food stuffs (pp. 219-254). London, UK: Applied Science Publishers Ltd.

[11]. Pigott, G.M. Tucker, B.W. 1990. Seafood. Effects of technology on nutrition (pp. 104e135). New York, USA/Basel, Switzerland: Marcel Dekker, Inc.

[12]. Ohshima, T. Shozen, K. Usio, H. Koizumi, C. 1996. Effects of grilling on formation of cholesterol oxides in sea food products rich in polyunsaturated fatty acids. LWT-Food Sci Technol. 29, 94-99.

[13]. Candela, M. Astiasaran, I. Bello, J. 1998. Deep-fat frying modifies high-fat fish lipid fraction. J.Agric. Food Chem. 46: $2793-2796$.

[14]. Sant'Ana, L.S. Mancini-Filho, J. 2000. Influence of the addition of antioxidants in vivo on the fatty acid composition of fish filets. Food Chem. 68, 175-178.

[15]. Tarley, C.R.T. Visentainer, J.V. Matsushita, M. deSouza, N.E. 2004. Proximate composition, cholesterol and fatty acids profile of canned sardines (Sardinella brasiliensis) in soybean oil and tomato sauce. Food Chem. 88,1-6.

[16]. Jucieli, W. Vivian, C.B. Cristiane, P.R., Andre'de, M.V. Tatiana, E. 2008. Effect of different cooking methods on the oxidation, proximate and fatty acid composition of silver catfish (Rhamdia quelen) fillets. Food Chem. 106,140-146.

[17]. Garcı'a-Arias, M.T. Pontes, E.A. Garcı'a-Linares, M.C. Garci'a- Ferna'ndez, M.C. Sa'nchez-Muniz, F.J. 2003. Cookingfreezingreheating (CFR) of sardine (Sardina pilchardus) fillets. Effect of different cooking and reheating procedures on the proximate and fatty acid compositions. Food Chem. 83, 349-356.

[18]. Saguy, I.S. Dana, D. 2003. Integrated approach to deep fat frying: engineering, nutrition, health and consumer aspects. J. Food Eng. 56:143-152.

[19]. Puwastien, P. Judprasong, K. Kettwan, E. Vasanachitt, K. Nakngamanong, Y. Bhattacharjee, L. 1998. Proximate composition of raw and cooked Thai freshwater and marine fish. J Food Comp Anal. 12, 9-16.

[20]. Gall, K. Otwell, W.S. Koburger, J.A. Appledorf, H. 1983. Effects of four cooking methods on the proximate, mineral and fatty acid composition of fish fillets. J. Food Sci. 48,1068-1074.

[21]. Gokoglu, N. Yerlikaya, P. Cengiz, E. 2004. Effects of cooking methods on the proximate composition and mineral contents of rainbow trout (Oncorhynchus mykiss). Food Chem. 84, 19-22.

[22]. Shirai, N. Suzuki, H. Tokairin, S. Ehara, H. Wada, S. 2002. Dietary and seasonal effects on the dorsal meat lipid composition of Japanese (Silurus asotus) and Thai catfish (Clarias macrocephalus and hybrid Clarias macrocephalus and Clarias galipinus). Comp Biochem Physiol Part A. 132(76), 609-619.

[23]. Danaé ,L. Siew, Y. L.E. 2010. Effect of cooking method on the fatty acid profile of New Zealand King Salmon (Oncorhynchus tshawytscha). Food Chem. 119, 785-790.

[24]. Ahlgren, G. Blomqvist, P. Boberg, M. Gustafsson, I.B. 1994. Fatty acid content of the dorsal muscle an indicator of fat quality in freshwater fish. J. Fish Biol. 45, 131-157. 